Accepted refereed manuscript of:

Munoz S-A, Macaden L, Kyle R \& Webster E (2017) Revealing student nurses' perceptions of human dignity through curriculum co-design, Social Science and Medicine, 174, pp. 1-8.

DOI: $10.1016 /$ j.socscimed.2016.12.011

(C) 2016, Elsevier. Licensed under the Creative Commons Attribution-NonCommercialNoDerivatives 4.0 International http://creativecommons.org/licenses/by-nc-nd/4.0/ 
Revealing student nurses' perceptions of human dignity through curriculum co-design

Sarah-Anne Munoz (corresponding author), Division of Health Research, University of the Highlands and Islands, An Lochran, 10 Inverness Campus, Inverness, IV2 NB, sarah-anne.munoz@uhi.ac.uk

Leah Macaden, School of Health Sciences, University of Stirling

Richard Kyle, School of Nursing, Midwifery and Social Care, Edinburgh Napier University

Elaine Webster, School of Law, University of Strathclyde 


\title{
Revealing student nurses' perceptions of human dignity through curriculum co-design
}

\begin{abstract}
Dignity is a slippery concept to define - yet it has been at the heart of media and policy debates around the provision of health and social care in recent years; particularly in the United Kingdom following the Mid-Staffordshire scandal and subsequent Francis Inquiry. This paper considers the concept of dignity in care from the perspective of student nurses. Thus, it allows us to discuss how professional nurses-to-be conceptualise dignity and also how they consider it should/could be taught at undergraduate and postgraduate levels of training, and as part of their Continuing Professional Development. It is only through understanding how student nurses conceptualise and experience human dignity, and the giving and receiving of dignity in care, that it will be possible to support its facilitation in the preparation of practitioners. This paper reports on findings from a series of participatory research workshops held with undergraduate nursing students in Scotland in 2013-14 that were designed to engage the students in the development of educational resources to support the teaching of dignity in care within the nursing curriculum. The outputs from each workshop, along with analysis of transcripts of the workshop discussions, demonstrate the value of co-design as a methodology for involving students in the development of interdisciplinary resources. We observed a desire from students to actively enhance their understandings of dignity - to be able to recognise it; to see dignity in care being practiced; to experience providing such care and to have the appropriate tools to reflect on their own experience. Overall, the research revealed a rich understanding of the ways in which human dignity is conceptualised by nursing students as an embodied practice, associated with memory and personal to an individual. It was understood by the students as shifting, experiential and fragile.
\end{abstract}


Key Words: UK; nursing; dignity; care; education; co-design

\section{Introduction}

Dignity is a debated concept (e.g. Düwell et al., 2014; Jacobson, 2007; Pullman, 2002) yet one that runs deep in social sciences literature on practices of care and in particular that of nursing, which is the focus of this paper (Jacobs, 2001). Jacobson's (2007) review of "dignity and health" identifies two facets to the concept: those of "social" and "human" dignity. She defines human dignity as the "inherent and inalienable value that belongs to every human being" and social dignity as the enactment of this "notion of universal value [through] behaviour, perception and expectation". As Jacobson's (2007) review demonstrates, both social and human dignity are pertinent to the delivery and study of health and care. In social sciences health research, dignity has been seen as an inherently important concept that sits at the heart of what it means to provide appropriate care to individuals. Often, dignity is something that is seen to be in need of "preservation" (Oosterveld-Vlug et. al., 2015) in the face of a hospital stay or care home residency. There are undertones that dignity is something that can be damaged when an individual is placed in a vulnerable position, such as being ill or faced with loss of function or death (Hall, Dodd and Higginson, 2014). Alongside this, therefore, is the suggestion that it is the place of the healthcare system and the healthcare professional in particular to maintain the dignity of the individual. Indeed, it has been defined as follows:

"Dignity in care shows how recipient dignity is maintained and enhanced through the respectful behaviour of care-givers." Jacobson, 2007, p. 7

Much research, therefore, that considers dignity within the healthcare setting, focuses on exploring how different types of patients understand and conceptualise dignity, with a view to informing healthcare professionals about what needs to be "preserved" and how. This research has recognised 
that dignity is a personally experienced concept; often within the context of how it is conceptualised and experienced by older people, the terminally ill (Chochinov et. al., 2002a; Chochinov, et. al., 2002b; Annette and Love, 2005), people with disabilities (Gibson et. al., 2012) or other "vulnerable" groups (Jacobson, 2007). General themes that run throughout this literature point to dignity (in care) being a multi-faceted concept that is about individuals' sense of self and self-control. It is also about how they are treated by care-giving staff, in terms of both medical intervention and the manner in which it is delivered (Jacobson, 2007; Oosterveld-Vlug, et. al., 2015). Thus, much research on dignity in health and care contexts within the social sciences considers the relational dimensions of dignity or, as Jacobson describes it, "social dignity” (2007):

"...the ways in which dignity is either maintained or threatened through social interaction in specific health-related situations" p. 299

In recognition of this inter-relational feature of dignity-respecting care, this paper adds to the literature by considering dignity from the perspective of one group of future health care professionals - nurses in training. Nursing has been called the "philosophy and science of caring" (Watson, 2008) implying that nursing education involves being taught how to provide care. Often it is nurses that are seen to be the primary providers of dignity within a healthcare/hospital setting. Some work has considered what dignity means to the nurse and how $\mathrm{s} /$ he can implement dignified care, e.g. Soderberg et. al., (1997). The question of whether dignity, as a concept, can be taught, as opposed to being an inherently held or intuitively grasped perspective of the nurse, has not been addressed in the literature. Although Matiti (2015) has called for the promotion of patient dignity to be included in nursing education in order to address perceived deficits, dignity education for student nurses is an under-researched area. More commonly, researchers have considered areas such as the teaching of concepts such as "empathy" (e.g. Richardson, Percy and Hughes, 2015), "ethics" (e.g. Numminen et. al., 2010) and "compassion" (e.g. Adam and Taylor, 2014). 
We consider student nurses in this paper, as they have been particularly under-represented in research relating to human dignity. It has been suggested that student nurses may feel particularly challenged in some areas pertinent to maintenance of dignity such as provision of intimate care (Crossan and Mathew, 2013). By considering the student nurse, we are able to understand perceptions of human dignity at the start of nursing careers, how these may shift over time, and address the question of whether, and if so how, dignity in care can be taught. This is an important question in light of recent media and policy debates that have urged nurses in particular to be more caring and respectful of patient dignity. Nurses in their advocacy role assume responsibility for the manner in which the patient's human dignity and other significant human values are respected and protected during illness Morra (2000). If there have been failings in provision of dignity in care, how can these be rectified? Should we include the consideration of the concept of dignity right at the beginning and throughout nursing training and professional practice? There are several reasons for wanting to do this - not least a moral argument for patient-centred care. Chochinov et. al. (2002: page) report that "one of the most compelling reasons for addressing the issue of dignity lies in the fact that prior studies have documented loss of dignity as the most common response given by physicians when asked why their patients had selected euthanasia or some form of self-assisted suicide." This places the concept, and maintenance of, dignity at the heart of life itself.

As noted above, Matiti (2015: p. 109) calls for dignity to be included in the nursing curriculum through inter-professional education that exposes nursing students to concepts of dignity beyond "the eyes of their own profession". The research reported in this paper formed part of a wider project, which tested such an idea with students from each year of an undergraduate nursing programme in Scotland. It did so by exposing students to non-familiar discourses around the concept of dignity. Students participated in workshops led by researchers interested in dignity from a legal (including human rights) perspective. These workshops confronted students with dignity narratives from, for example, 
Holocaust testimony and European human rights case-law. By allowing students to engage with resources, not only from beyond their own profession but from beyond a healthcare context, the workshops aimed to provoke deep reflection on students' own conceptualisations of human dignity. The research project then gave students an opportunity to channel these conceptualisations of dignity, in light of their own experiences of dignity in care and their nursing instruction to date, into decision-making about effective resources for dignity education.

\section{Methods}

A participatory research approach was deemed appropriate to answering the research question of whether, and if so how, dignity education can be part of the undergraduate nursing curriculum. Such an approach involved undergraduate students directly in addressing the research question and in decision-making relating to the design of educational resources that could be included within the nursing curriculum. This allowed us to value the experience and knowledge of the students themselves, placing their voices at the core of the research. Participatory research involves those traditionally subject to the research "gaze" in the research process itself, and has been used successfully in healthcare and nursing research to, for example, involve nurses and other healthcare staff in research to improve working conditions and patient experience (e.g. Tanabe et. al., 2008; Tanabe et. al., 2009, Cameron et. al., 2010); involve patients and communities in service developments and improvements (e.g. Foster et. al., 2010; Liu et. al., 2011; Hingle et. al., 2013) and in curriculum development (e.g. Coetzee, Britton and Clow, 2005). A participatory research framework has thereby been used elsewhere to effectively engage health care professionals with services (re)design.

We structured this approach around a series of workshops with 35 student nurses across years 1-3 of an undergraduate programme at one Scottish university; three workshops with (12-16) students from 
each of the three cohorts. The research took place over the 2013-2014 academic year and ethical approval was obtained from the School Research Ethics Committee of the University.

A workshop was held with each of the student year groups, with each workshop building on the output of the previous one. The first took the format of a serious game in which students used a board and theme cards to reach consensus on the 'what', 'how' and 'why' of dignity education within the nursing curriculum. The outputs from workshop 1 were then used to construct a timeline of dignity education from first year through to working as a nurse - we used a voting technique to achieve a consensus on the elements of the timeline with the workshop participants. This timeline was used to devise a 'storyboard' of the nursing education journey - it consisted of a series of posters with both textual and visual illustrations of the ways in which the students felt dignity education could best be included in the nursing curriculum. Each poster also contained a large blank area for comments. In workshop 3 , students considered a printed version of the storyboard and added their own comments. A final version of the storyboard, and hence the students' perceptions of how dignity education could be included in the curriculum, emerged from this final workshop.

Observational notes were taken by the researchers at each workshop. The student discussions were also recorded using a digital voice recorder and transcribed by a professional transcription service. The first stage of our qualitative analysis involved taking a thematic approach (Braun and Clark, 2006) to our textual sources (notes and transcripts).Through familiarisation with the data, we developed an initial set of codes relating to the ways in which the students spoke about human dignity and dignity in care. This grounded approach allowed us to start with the students' perceptions of dignity in their own words and build our thematic categories from an examination of their own meaning-making. These were coded by hand on paper copies of the textual sources. Following this we were able to identify latent themes grouping together perceptions of dignity in care and pedagogical strategies for dignity education. The codes were agreed and coding reviewed by all authors in order to enhance robustness. 


\section{Results: Understanding Student Nurses' Perceptions of Dignity in Care}

As outlined above, our participatory methodology led to the co-creation with nursing students of a timeline, or storyboard, representing how they felt dignity education could, and should, be included in the nursing curriculum. Analysis of the conversations and discussions held by the students during this co-creation process, allowed us to identify common themes relating to how these student nurses understand the concept of dignity and how this can be implemented in a care setting. It was through analysis of the co-design process (the discussions it involved) and its outputs that we started to see not only what would be effective pedagogically from the students' own perspective but also how these future professionals understand dignity in a conceptual and practical sense. It is essential that any pedagogical strategies take these perceptions into consideration. This section of our results presents the perceptions of dignity in care held by our participants - these underlie the pedagogical strategies suggested by the students for dignity education that are presented in the following section.

Above all, the way in which the student nurses' spoke about dignity demonstrates that it is an embodied practice. From the outset of their training, students nurses are involved in engaging their material bodies, senses and emotions in the practice of 'being' a nurse (Draper, 2014). Our students seemed to intuitively apply this thinking to their understandings of dignity in care - expressing these in ways that foreground the importance of the material body and its senses in the identification of patients' needs and being the vehicle through which they can offer dignity to patient:

"..if you don't have genuine compassion for a human being then em, you're not going to treat them as dignified as somebody who does genuinely care about how they feel and generally want their best interests..." Oliver, Year 2

"...'Cause I think [an understanding of dignity] it's just something which is within you that probably needs enhancing, yeah, it's something ...that you've got already ..." Jessica, Year 3 
"there's been patients lying in bed, you're doing personal care and the staff are chatting to each other, ignoring just doing the service or personal care, completely ignoring, just even turning without even asking the patient, it's taking away from human dignity ..." Emily, Year 2

Our work demonstrates a rich understanding of the ways in which human dignity, and the capacity to facilitate this for others through a care setting, is understood by student nurses as embodied practice. They talk about it, for example, as being personal to the individual, and something that is 'deep within' or associated with a lot of thoughtful reflection on the part of an individual. They relate dignity to an individual's feelings of self-worth and power(lessness). It is often conceptualised by the students as something unspoken but demonstrated, or enacted, through the physical actions of the material body.

As such, the students see the enactment of providing dignity in care as something with the potential to become habitual - etched into the ways in which they routinely use their bodies to deliver care. It is something that is seen as being experienced both emotionally and physically by patients:

“...this gentleman, you know he likes to have his, he's, he's shaved every single day, he likes to have that, you know you can't leave him otherwise he doesn't like it. You know he couldn't? speak or anything but that was what was, you know that was his ... you know things that he liked to do, which was respecting his dignity at the same time ..." Grace, Year 3

The ways in which our student nurses spoke about dignity also demonstrate that they understand that perceptions and understandings of it are not fixed but change over time and between spatial contexts:

"And I think it would, I think your perception of dignity from year one compared to year three will be different; I defy anyone not to be changed from year one to year three, and I think it would be a journey that everyone would take..." Sophia, Year 3

They understand that there is a difference between how they think about dignity in the classroom and how they think about it in the ward. When they talk about dignity in care, they demonstrate that they understand it as fragile; something that can damaged over time or compromised by external factors. 
Student discussions of enacting dignity in care are intricately bound-up with their understandings and experiences of the power relationships within healthcare settings and healthcare professional hierarchies.

"... I think where the problem can be is when you're actually [out on practice] and the culture in that particular ward and the particular staff that are in there, and very often things like time and understaffing etc., that, and people who are more task-orientated and time-orientated, and you can, you know it's very difficult to sometimes feel like the only who's thinking 'come on, what, why, why are we, what are we doing with this human being [and] why are we trying to rush this poor person,' when everybody else seems to be "right we need to get them up and ready by this time 'cause Dr so and so for the ward round," and I think it's very difficult, quite a difficult thing to stand up and say "hey, what about this person, why are you rushing this poor man,' you know he's going to be distressed all day now ..." Oliver, Year 3

"...but I think dignity depends on the ward environment and the staff, time management, the running of the ward, if you're in, like we're students, and we're going to our first job and that ward has been run like this for years, and years which means breakfast is at eight, and that is it. You get them up either before em, or after breakfast, dinner is at 12, supper's at five - whether they want it or not..." Ava, Year 3

They see their own enactment of providing dignity in care as a potential rebuke against an "institution" or a "system" that minimises the opportunities for dignity to be maintained. Being able to practice dignity in care is seen by the students as a way to challenge the culture of particular healthcare settings. The students generally perceived this as a culture which facilitates a task / document focussed rather than a person centred approach to care resulting in compromises with dignity in care primarily due to resource constraints with time, staffing levels, and finances to invest in staff development and training. 


\section{Results: CanDignity' be Taught? A Nursing Education Journey}

The ways in which the student nurses conceptualised dignity (in care) undoubtedly influenced their response to whether dignity education could, or should, be included in the nursing curriculum. Through the participatory workshops, the student groups reached a consensus that there was value in considering the concept of dignity, and how it is experienced in the healthcare context, explicitly in the nursing curriculum. The storyboard that was created in outlined in this section of the results - it includes pre-university and post-graduation stages at the request of the students, who felt it was important to think about dignity in care not only within the defined undergraduate training programme.

\section{FIGURE ONE}

Figure 1 shows the storyboard - focusing on the illustrations and resources (for dignity education) agreed by the students. The specific resources requested span the "experiential and experimental pedagogical strategies" identified as useful through other areas of our research (in review).

\section{Applying for a University Course}

In terms of the timing of such strategies within the nursing curriculum, it can be seen in Figure One that the students felt consideration of the concept of human dignity, and the capacity for the provision of dignity in care, is something that needs to be considered even before individuals are enrolled on an undergraduate nursing programme. They felt that the capacity to provide dignity in care was, in part, a characteristic that prospective nursing students should possess before starting the nursing programme and that this should be assessed at the application stage. It was suggested that a questionnaire should be included with university applications in order to assess whether candidates valued dignified care, which could then be assessed further during the personal interview stage of student recruitment: 
"... we thought [this] was actually quite important... because ... at the interview stage, this could be something that could be discussed at the interview; it could be like a questionnaire and then individual work that could be part of the actual application form, it could be actually a discussion about dignity, 'cause we think it's the crux of it all; we go on about patient-centred care, but actually it's dignity that underlies all of it ..." Sophia, year 3

In the Classroom

As the storyboard moves through the different undergraduate years and into professional nursing, it tells us about the types of interdisciplinary resources that nursing students value in relation to the teaching of dignity in care and how they think these could and should be included in the curriculum. It can be seen that the students divided the types of resources between two different situations that they encounter as undergraduates - learning in the classroom and learning on placement, or practice.

Students valued the inclusion of discussions of the concept of dignity within the traditional classroom or lecture-based context, particularly in the earlier stages of the undergraduate programme. In the first year, they suggested lectures should include invited external experts from disciplines other than nursing or healthcare to give examples, discussion and critique of the concept of dignity as pertaining to their own disciplines. This was partly in response to the students' engagement with our wider project on dignity in care that included the workshops led by legal academics (as noted above). During the participatory workshops, students reflected on what they saw as the value of taking part in these human rights-based workshops and asked for the inclusion of similar text-based scenarios within the curriculum:

"I think just everyone else's views on it and getting their take on it, I think you sort of think about things, you know 'cause you usually only have your, your way of thinking, and when you hear others you think 'oh well maybe, mmm yeah, I think so,' you know, so ... It's really interesting to hear other people's views, particularly when we were discussing the human rights and that, that was ... ... really mind- 
opening, you know... you can see how people could look at it a completely different way, and it was interesting, you think 'gosh ...,' you know 'that's interesting that someone's seen it like that, or 'oh, I didn't think I would see it like that,' or, or that something like that would affect me so much, and some people were affected so much by one story but, I mean you were, but another story totally stood out to you and then you think 'why is that, why did that one ... why didn't that one stand out to me like it did with everyone else?..." Sophia, year 3

The students felt, however, that the inclusion of first-hand patient narratives would also be of benefit. Students asked for the inclusion of such narratives in both years one and two - as a precursor to first placement and then as a tool to help them reflect on previous placements as they progress through the undergraduate programme. Student discussions frequently highlighted their desire to deal with the concept, and teaching of, dignity as an on-going concern throughout the nursing programme. In this context, they asked for lectures in year three to recap on understandings of dignity developed over years one and two.

\section{In Practice}

As students moved from the classroom into practice, they wanted to have tools at their disposal to help them stay mindful of the provision of dignity in care. They wanted to be supported to both reflect on their own practice and that of other healthcare workers that they observed and came in contact with during their placements. First year students worried that they would feel time pressured on their placements and fail to remember to consider dignity; second and third year students often reflected on personal experiences of placements where they felt they had not been able to foreground dignity in care because of the organisational culture of the wards and healthcare settings into which they were placed. There was often a discourse in which students described themselves as wanting to provide dignity in care and being cognisant of this, in opposition to the "older" or "more experienced" nurses whom the students felt were not cognisant of dignity or not able to prioritise it sufficiently to devote enough time to its preservation: 
“... and I think it's, it's a, a sad truth, but I think a lot of people do just conform to fit in, and especially like you know, you're nervous going on a placement, you want the staff to you like you, so you just pick up their bad habits and then, like especially with your first placements, the habits you pick up in your first placement go through you, or with you, for the rest of your, your training and ..." Emily, year 2

"... even some of the, you know, older ones that have been there for longer ... personally I don't think they will change, I think they're just waiting for, however many years 'til retirement and then they'll finish, that's, but that's my [laughs] personal opinion ...' Oliver, year 2

... you can't say anything to them or, you know, and I think that's just one of the barriers we face ... but then again you've got to think of 'well this is me, I'm going to do this my way and not... you know the way they would do it... Lily, mental health student, year 3

...But it's difficult to challenge somebody though when if, if you, you know if you challenge somebody and say 'well, em, would that ... would, did you have to do it that way, I thought that was a bit rushed ...,' or whatever, and they can get very defensive "oh, you know I've been on this for 40 years," and ... Oliver, year 2"

Related to this was a desire by the students to include a section on 'working as a nurse' within the storyboard. Within this section is recognition of their opinion that professional nurses would benefit from continued professional development that allowed for on-going activities related to the structured consideration of dignity in care practices.

Students suggested that some type of formalised diary keeping would allow them to record their experiences and reflections on placement in relation to dignity in care. It was suggested that this would help them reflect on how to put into practice the concepts of dignity previously discussed in the classroom. The students were keen to have a reflective element within the curriculum in relation to dignity. In the first year placement context, some students felt written diaries would be helpful, 
whereas others suggested they would prefer online or even text-message based systems to help them record their reflections; as illustrated in this conversational excerpt:

"If it could be done ... you could text it to a number that then make it be online, you know, you could do it straightaway if you went down into the changing rooms, text it, well text what you were thinking to the number that uploaded it to your personal site." Olivia, year 1

“...Yeah like Twitter type thing, it's just 140 characters and you just say the, your thoughts of that day summarise it and its done because I think the prospect of writing a diary is a bit like... [? expression of dislike]..." Amelia, year 1

“...It's a bit lengthy." Isla, year 1

\section{Discussing Dignity in Care}

Students highlighted a desire to be able to speak to various stakeholders about the concept of dignity and their experiences of practising dignified care. Not least, they argued for the inclusion of structured opportunities to speak to other students in their same year group on the issue. It can be seen in the storyboard, for example, that small group discussion with other students was agreed as being beneficial for inclusion in the curriculum at the year two stage. Students reflected on the potential benefits of sharing experiences gained on placement and being able to talk through practical ideas on how to put dignity in care into practice:

“...Small groups I think would be better, you know, I'd rather talk to ... done in a small group and you can keep up with people's ideas because what you find is people are happier to talk in a small group dynamic, I am..." Isabella, year 2

It was also suggested by the students that they would benefit from structured time to reflect on dignity in care, following their practice placements, with their mentors. In the third year, students suggested the inclusion of time to allow them to comment on situations and scenarios that deal with 
considerations of dignity in care - particularly as they started to think about transitioning into registered nurses and being exposed to different types of clinical scenarios than they had experienced as undergraduates. While some students argued for the use of role-play, others emphasised that they would rather engage with situations and scenarios in a more individually reflective manner, such as the use of personal reflection on videos:

"...and we thought we could have it in the classroom where we would have like different scenarios, and we would have like role playing where you were the person giving the care, and then you were on the opposite side where you were actually receiving care... where you know like you're in a bed and you're getting moved about and like different scenarios like that where you can actually ... feel how somebody else would feel in that situation..." Ava, year 3

Thus, the storyboarding allowed us to understand the educational resource types that undergraduate nursing students felt could be effective around dignity education in different contexts. We observed, for example, their desire for tools to both include reflection on dignity within the classroom and the practice settings. The students argued for both an inclusion of discussions of the concept of dignity within the traditional lecture situation but also for structured opportunities for them to speak about their own understandings and experiences of dignity in care within, for example, peer support situations. The students emphasised the need for tools to help them reflect on the meaning of dignity, how they may implement it in their own practice, and how they might observe it, or its absence, in their placements. The use of situations and scenarios was suggested as a way to understand what it is like to both give and receive dignity in care.

The analysis of the storyboard and the workshop discussions has, therefore, revealed key themes in relation to the students' perceptions of how dignity education could and should be included in the nursing curriculum. It has shown that the students have a desire to actively enhance their understandings of the concept of dignity, both within and beyond the nursing or healthcare context, 
seeing the development of a more nuanced understanding of the concept itself as the foundation for them to then implement dignified care practice.

\section{Discussion: Dignity Education within the Nursing Journey}

Our results have shown the ways in which one group of student nurses conceptualise dignity in care. We have seen that they discuss dignity initially in terms of human dignity or, in general terms, the value placed on human life that is intuitive or inherent (Nordenfelt, 2004). They talk of dignity as being something that is felt "deep within" and held inside the bodies of both nurses and patients. The students talk about patients being able to "lose" dignity and nurses being able to "provide" dignity. Many students felt it was their own inherent sense of dignity that allowed them to sense or ask patients about their needs and, therefore, adapt their ways of moving, speaking, touching and behaving in order to allow the patient to maintain their own inner sense of dignity. Ultimately, therefore, we can see that the nursing students conceptualise the relationship between the body of the patient and the physical enactment of nursing as the mechanism through which dignity can be enhanced or threatened. This suggests that the processes identified by Soderberg et. al. (1997) in relation to the translation of practising nurses' understandings of dignity into ways of doing nursing is understood, although perhaps not articulated explicitly, at the undergraduate level.

The students' conceptualisations of dignity can be seen to underlie the choices they made in relation to how dignity education could be included in the nursing curriculum. The different resources that the students agreed to include within the curriculum fall into five broad types, according to the students' motivations for including them: a desire to i) recognise dignity, ii) observe dignity in care happen, iii) experience providing dignity in care iv) reflect on dignity in care and v) refresh their understandings on an on-going basis. Thus, their storyboard reflects these themes with the inclusion of resources and tools designed to: 
i) Recognise: expose them to the concept of dignity as it is defined and used within healthcare and other contexts, in order to enhance their understanding of it; particularly through exposure to multiple interpretations and memorable examples.

ii) Observe: expose them to situations and scenarios in which they can observe the provision of dignified care through both actual placement situations but also the use of patient stories, video and other virtual means.

iii) Experience: allow them to experience providing dignified care, again both through placement and simulated situations in face-to-face and virtual contexts. For example, situations in which the student can simulate the experience of being the patient.

iv) Reflect: assist them to reflect on dignity in care. Prompts such as diaries to encourage students to take notes on experiences of dignity, or lack of dignity, in their placements and to discuss it with each other.

v) Refresh: build educational tools into CPD to allow continued reflection over time.

Thus, our co-design process allowed us to understand five underlying characteristics important to dignity education from the perspective of our student nurses.

The notion that dignity is intuitive and personal is reflected in the students' desire to "recognise". Notions of the shifting, context specific nature of dignity are related to the desire to "observe", "reflect" and "refresh". The conceptualisation of dignity as embodied is highlighted in the inclusion of experiential educational methods.

A key characteristic that emerged from the student discussions and storyboarding was the need for regular refresher updates over time - to reinforce their understandings of dignity; to revisit their conceptualisations as they moved through the undergraduate programme and were perhaps exposed to new situations that shifted their understandings of dignity and dignity in care. Third year students in particular reflected on this and how they had experienced shifting understandings of dignity over time (although all year groups discussed what they perceived as a need to include dignity education 
throughout the nursing programme and into working life through continued professional development). There was consensus that education around dignity should not be treated as a 'one off' topic, covered, for example in a year one lecture and then not revisited. Instead, the student nurses saw the opportunity for continued reflection and consideration of dignity to be essential both for their personal and professional development into nurses who confidently provide dignity in care.

Our work has, therefore, highlighted the importance of understanding student nurses perceptions of dignity in relation to the inclusion of dignity education within the nursing curriculum. Further work is needed, however, to investigate this topic beyond the Scottish/UK context in which our study was situated. Although we included students from all years of the under-graduate programme, the key limitation associated with the study is our relatively small number of participants who were all studying at the same university.

\section{Conclusions: Dignity Education in Nursing}

This paper has considered the concept of dignity in relation to the delivery of care by nurses. It has done so by considering the point of the view of student nurses within each year of an undergraduate programme at one Scottish university as expressed through discussions in a series of participatory workshops.

An understanding of human dignity as embodied, shifting and fragile was shared across the three under-graduate nursing year groups included in our study. Their understandings can be seen to relate to existing conceptualisations of human dignity (the inherent value of human life) and social dignity (dignity that is enacted through relationships). However, all of the students agreed that their understandings of dignity had changed over time - and stressed the desire to engage with concepts and examples of dignity throughout their training and subsequent professional practice; as well as to be exposed to examples from outside the healthcare context. This suggests a real enthusiasm within 
the student body to engage with the concept of dignity, reflection on its meaning and how it can be translated into the care practices enacted by nurses on a daily basis - something that could be harnessed within the undergraduate, post-graduate and continuous professional development curricula for nurses. This could support nurses who want to ensure that they are able to deliver care that is as dignified as possible for each individual patient.

The findings presented in this paper have allowed us to reflect on how and when particular types of "experiential and experimental pedagogical strategies" as identified in other areas of our work (under review) could be incorporated into the nursing curriculum. Through analysis of the workshop outputs and associated transcribed discussions, we have been able to suggest a typology for the inclusion of dignity education resources within the nursing curriculum that is sensitive to nursing students' conceptualisations of human dignity as embodied, shifting and fragile: i) recognise, ii) observe, iii) experience, iv) reflect and v) refresh.

We used a co-design approach to work with the student nurses to design solutions for including the topic of dignity within the under-graduate nursing curriculum. Taking this approach allowed us to develop a timeline of education needs, and associated resources that is grounded in enhancing the way that student nurses understand dignity as embodied, shifting and fragile. This can be translated into educational materials and tools that allow them to engage in dignity 'learning' through processes of recognition, observation, experience, reflection and refreshing. Co-design has helped us to understand how interdisciplinary resources can be of value because of the ways that they speak to nursing students' understandings of dignity, their desire to see this within their curriculum and to be/come nurses that provide dignity in care. Building on the ways in which student nurses intuitively understand dignity may be an effective means for developing ways to encourage dignity 'learning' at all levels of nursing training and practice.

However, our research has also highlighted that putting knowledge of dignity (in care) into practice as a nurse is seen by the students as challenging because it is bound-up with the power relations inherent 
in healthcare settings. The students spoke of organisational, professional and managerial barriers to the implementation of dignity in care as they saw it. The conceptualisation of dignity that is reflected in our research with students is one that is compassionate and patient-focused - the students see the enactment of this as a challenge to the established power relationships within healthcare settings. There may be the potential to look at ways of harnessing this enthusiasm to facilitate wider cultural change within healthcare settings and teams.

\section{References}

Adam, D., Taylor, R., (2014) 'Compassionate care: empowering students through nurse education', Nurse Education Today, 34 (9), pp. $1242-1245$

Braun, V., Clark, V., (2006) 'Using thematic analysis in psychology', Qualitative Research in Psychology, 3, pp. $77-101$

Cameron, K., A., Engel, K., G., McCarthy, D., M., Buckley, B., A., Kollar, L., M., M., Donlan, S., M., Pang, P., S., Makoul, G., Tanabe, P., Gisondi, M., A., Adams, J., G., (2010) ‘Examining emergency department communication through a staff-based participatory research method: identifying barriers and solutions to meaningful change', Annals of Emergency Medicine, 56 (6), pp. $614-622$

Chochinov, H., M., Hack, T., Hassard, T., Kristjanson, L., McClement, S, Harlos, M., (2002b) ‘Dignity in the terminally ill: a cross-sectional, cohort study', The Lancet, 360, pp. $2026-2030$

Coetzee, M., Britton, M., Clow, S., E., (2005) 'Finding the voice of clinical experience: participatory action research with registered nurses in developing a child critical care nursing curriculum', Intensive and Critical Care Nursing, 21 (2), pp. $110-118$ 
Crossan, M., Mathew, T., K., (2013) 'Exploring sensitive boundaries in nursing education: attitudes of undergraduate student nurses providing intimate care to patients', Nurse Education in Practice, 13 (4), pp. $317-322$

Draper, J., (2014) 'Embodied practice: rediscovering the 'heart' of nursing', Journal of Advanced Nursing, 70 (10), pp. $2235-2244$

Düwell, M., Braarvig, J., Brownsword, R., \& Mieth, D. (Eds.). (2014). The Cambridge Handbook of Human Dignity: Interdisciplinary Perspectives. Cambridge: Cambridge University Press.

Foster, J., Burgos, R., Tejada, C., Caceres, R., Altamonte, A., T., Perez, L., Noboa, F., R., M., Urbaez, M., F., Heath, A., Hilliard, C., Chiang, F., Hall, P., (2010) 'A community-based participatory research approach to explore community perceptions of the quality of maternal-newborn health services in the Dominican Republic', Midwifery, 26 (5), pp. $504-511$

Gibson, B., E., Secker, B., Rolfe, D., Wagner, F., Parke, B., Mistry, B., (2012) 'Disability and dignityenabling home environments', Social Science and Medicine, 74, pp. $211-219$

Hall, S., Dodd, R., H., Higginson, I., J., (2014) 'Maintaining dignity for residents of care homes: a qualitative study of the views of care home staff, community nurses, residents and their families', Geriatric Nursing, 35 (1), pp. $55-60$

Hingle, M., Nichter, M., Medeiros, M., Grace, S., (2013) 'Texting for Health: the use of participatory methods to develop health lifestyle messages for teens', Journal of Nutrition Education and Behaviour, 45 (1), pp. $12-19$

Jacobs, B., B., (2001) 'Respect for human dignity: a central phenomenon to philosophically unite nursing theory and practice through consilience of knowledge', Advances in Nursing Science, 24 (1), pp. $17-35$ 
Jacobson, N. (2007). 'Dignity and health: a review', Social Science \& Medicine, 64. pp. 292 - 302Liu, J., McCauley, L., Leung, P., Wang, B., Needleman, H., Pinto-Martin, J., (2011) 'Community-based participatory research (CBPR) approach to study children's health in China: experiences and reflections', International Journal of Nursing Studies, 48 (7), pp. $903-913$

Matiti, M., R., (2015) 'Learning to promote patient dignity: an inter-professional approach', Nurse Education in Practice, in press corrected proof.

Morra, M.E. (2000) 'New opportunities for nurses as patient advocates', Seminars in Oncology Nursing, Volume 16, Issue 1, February, Pages 57-64

Numminen, O., H., Leino-Kilpi, H., van der Arend, A., Katajisto, J., (2010) 'Nurse educators' teaching of codes of ethics', Nurse Education Today, 30 (2), pp. $124-131$

Pullman, D., (2002) 'Human dignity and the ethics and aesthetics of pain and suffering', Theoretical Medicine, 23, pp. $75-94$

Richardson, C., Percy, M., Hughes, J., (2015) 'Nursing therapeutics: teaching student nurses care, compassion and empathy', Nurse Education Today, in press corrected proof.

Soderberg, A., Gilje, F., Norberg, A., (1997) 'Dignity in situations of ethical difficulty in intensive care', Intensive and Critical Care Nursing, 13, pp. $135-144$

Tanabe, P., Gisondi, M., A., Barnard, C., Lucenti, M., J., Cameron, K., A., (2009) 'Can education and staff-based participatory research change nursing practice in an era of ED overcrowding? A focus group study', Journal of Emergency Nursing, 35 (4), pp. 290 -298

Tanabe, P., Gisondi, M., A., Medendorp, A., Engeldinger, L., Graham, L., J., Lucenti, M., J., (2008) 'Should you close your waiting room? Addressing ED overcrowding through education and staff-based participatory research', Journal of Emergency Nursing, 34 (4), pp. $285-289$ 
